\title{
Reflection on the Assessment of a Math Problem in a China Elementary School
}

\author{
An-ning CHEN \\ School of mathematics and statistics, Longdong University, Qingyang Gansu 745000, China;
}

\begin{abstract}
The assessment of a math problem in a China elementary school manifests that the math teacher is now still keeping to the obsolete notion of school education, attaching more significance to the result instead of the process of classroom instruction and adhering more importance to the standardized criteria in making assessment. Accordingly, it is proposed that the math teacher in the China elementary schools ought to hold the new and feasible concept of assessment, establish the assessment system with multiple dynamic objectives and diversified methods of assessment, highlighting the essential role of students and the process as well as the progress of assessment, with a purpose of promoting the comprehensive progress of students.
\end{abstract}

Index Terms - an elementary math problem, assessment, reflection

\section{Bringing out of the Problem}

The teaching evaluation is an important step for primary math teaching. It has direct direction; incentive and diagnosis function for teaching of Primary math. <Compulsive Education for Math Curriculum Standards> (2011 edition) points out that the main purpose for study evaluation is to understand the process and results of students' math study and encourage the students to learn as well as improve the teachers' teaching. The multiple targets and multiple methods evaluation system should be established. And the evaluation should both pay attention on the students' study result and the study process; Also they should both pay attention on the math study level of students and the emotion and attitude the students show in the math activities so as to help students to know themselves, and establish confidence[1]. With the continuous deepening revolution of new curriculum, the new education concept and the education nurturing target will have fundamental change while the teaching evaluation is playing more and more important role in math education. To some degree, it has been becoming the determinate factor for affecting the new curriculum revolution. Therefore, teachers should carefully comprehend the curriculum standard spirit and change it to the teaching evaluation concept while abandoning the evaluation defects in traditional education and put the education evaluation completely through the math teaching process. Only when this can be achieved, the new innovative talents that is fit for the time development needs with healthy mental and physical quality and knowledgeable and with capacity can be nurtured. Bringing out of the problem.

But the long term generated fixed evaluation concept is still lingering on under the current traditional education system and cannot be adapted to the new situation to satisfy the requirement of quality education. And to some degree it also seriously affected students' math study, especially the existing current teaching evaluation has backward concept and single evaluation way. It over emphasize the classification and selection function. This is shown especially in math teaching. The teachers all pay much more attention on the result when doing the evaluation for the students 'class performance, homework, and overemphasize the unique result and standard answer. For the individual creative thinking pattern that the students show in the math study, they will judge this as an error etc. with such evaluation's existing, not only will it not be in accordance with the new curriculum's proposed evaluation concept, but also will be disadvantageous for the students' innovative capacity. And this will gradually lead the loss of internal motivation for the study of math in such study progress which is indispensible. And further the students will lose the interest and confidence in math study.

\section{Case Display}

In one middle term math examination for grade two students, there is such an correction problem on the exam 29

paper with the vertical formula as: $\frac{+7}{99}$ and horizontal formula as: $29+7=99$. And the author finds that one kid's 29

calculation is, $\frac{+70}{99}, 29+70=99$ but the teacher gave a " $x$ " to such calculation. That means the child's calculation is wrong. And the child is also repeating the same sentence: "I don't think I did wrong. It is correct!' for the doubt brought about from the child, at that moment the author cannot say anything. From the years teaching experience of the author as the math teacher, the author believes the child's calculation is correct, or at least " $x$ " should not be given and the author cannot understand the teacher's evaluation for the moment.

\section{Case Analysis}

In the primary math teaching progress, how to correctly evaluate the role is the problem that every teacher should solve. For the above evaluation shown as above case, after discussion with the primary math teacher, the author finally understands: on one aspect, the school use the exam marks to evaluation the teacher's teaching so as to make the teaching of every teacher fair. Teachers all have prepared the standard answer before exam. When reading the paper, those are in accordance with the standard answer can be counted as correct and otherwise as wrong. And the author let the child to check the calculation from other students and the results certified 
this point as the standard answer is $\frac{+29}{36}, 29+7=36$. And most students did so. On the other hand, the teacher hasn't thought about the remedy of calculation formula to maintain the result as correct instead they just want to maintain the calculation formula and finally this leads to the beforehand mentioned evaluation. And for further analysis from this case, we can see that:

Firstly, it reflects that the teacher hasn't known what the real purpose is for the exam subjects. And the author thinks this subject is going to check the understanding of "Integer addition calculation principle-the vertical addition formula) (that is when doing such calculation, the same digit position should be aligned, that is only those with the same digit can do the addition directly and when the digit is complete in decimal then go further with one added on). If the teacher understands this point, then they should confirm the child's doing and the author thinks: for the kid who has added 0 behind 7 and equals to 99 can better understand "integer addition calculation principle" and has deeper thinking than the students who take 7 one more digit behind to calculate 36 to some degree. Because the students who add 0 behind 7 has achieved the principle that the same digit is aligned and those students have the 36 result might have practiced too much that they have already formed a fixed thinking pattern. That is their understanding of "Integer addition calculation principle" just lingers on the mechanical memorizing level instead of understanding deep level.

Secondly, because the teacher doesn't know the real purpose of the exam subject, he naturally takes evaluation changed as simple "standard answer" contrast. That is to take "standard answer" as the only one standard to weigh the students' correct and wrong behavior and do not pay attention or seldom pay attention on the students' problem solving thinking progress. Under the premises of mastering the "integer addition calculation principle" for the two activity, obviously the one to add 0 behind 7 has much more higher level thinking and wider thinking; however to move the 7 to the unit digit might be the behavior that the students used to adopt believing 7 as one digit number and cannot write in decade position. if students do so, it is actually a repeated mechanical training result and that disobeys the new curriculum's proposed math learning methods. And in this case, the teacher's evaluation is actually a habitual thinking patter. It is to teach students to do mechanical training or operate the "integer addition calculation principle" instead of paying attention to understanding and application of the principle itself.

Thirdly, the author thinks that the student adding 0 to 7 does not only correctly answered the question, but also broadened his own horizon and diverted his thinking. Besides he also mastered a kind of learning method that is correction is not only to correct the result but also when maintaining the result unchanged he can change the known conditions and finally make students to divert their thinking pattern and innovation and achieve effective training for flexibility of thinking pattern.
Fourthly, the evaluation has also arisen our thinking for such a problem: how to nurture the students' innovative capacity based on text contents and students' reality for middle and primary school students effectively? According to the author, he believes that adding 0 to 7 and equaling 99 such calculation and compared with regular calculation-move 7 to unit position, the previous calculation is a breakthrough creation of regular thinking patter. And this doing has acquired the teachers' positive affirmation and encouragement and such creative thinking pattern spark should have been taken care of by the teacher and making them develop as a flaming ground with hotter and more fire. But it just received a " $x$ " from teacher to disappoint the student like pouring a basin of water and extinguish the fire relentlessly.

Fifthly, some of the primary math teacher in the case reflects that they are not good at thinking backward on their teaching and easily to ignore the students' individual thinking, and their evaluation concept is old and method is single also they just pay attention on result and less on progress and they lack of nurturing for students on their creative ability.

\section{Case Introspection}

"Why our school never brings out talents?" this is the famous question brought about from Xuesen Qian. And this question has always been the hard and deep proposition in Chinese education career. And it needs the whole education circle and even the whole social circle to solve together. When seeing such evaluation from teacher, the author thinks that the teacher's evaluation concept and method are over too fixed and dogmatist and stubborn. They only pays attention to the result instead of progress and never listen to the students' individual thinking and in the long run, the students will lose interest and confidence for learning math and will be more disadvantageous for the nurturing of the students' innovation capacity. And the author feels painful for this, the children's future and also for our education which still has such evaluation concept. How can we let such evaluation to survive so long?

\section{A. How to change the evaluation concept}

The concept for new curriculum is to promote the development of every single student and lay a solid foundation for their life time learning and development. The purpose of evaluation is on one hand to understand fully the students' learning progress and results of math study and encourage them to study so as to promote their full development. On the other hand it is to help teacher to summarize and introspect through the evaluated information and change and improve the teaching contents and teaching process so as to improve the teachers' professional growth. The evaluation for students should be with development idea and pays much attention on the multiplication of evaluation contents and methods. That is the evaluation cannot only pay attention on the result but also on the study progress which shows the individuality and thinking and quality. And also this should pay attention on their emotional attitude and value concept. The way to evaluation should take the positive encourage and praise as the main way and dig the shining point in the students not to hurt 
the students' self esteem and self confidence; to pay respect to the students' work result and encourage them to boldly innovate and make a democratic, equal, harmonious learning atmosphere for the students. However cases such as this evaluation, the teacher is prone to encourage students to do exams or questions as the "standard answer" requires. And in the long run, the students will not have their own thinking and lose their own proposition and also individuality. And this will finally lead to the students' individuality's hard development. While the individual talent cannot exist, then where starts the innovation. Therefore, the teacher has to execute the new curriculum's evaluation concept based on the quality education to develop evaluation and takes the quality education value concept as the evaluation direction in the whole evaluation work and in every single stage. In the teaching, the teachers should put "what the students learned "as the priority and the excellent answer, unique solution, innovative thinking should be given confirmation in time and fully. The teachers should encourage and praise the students to communicate with other students for different solution and thinking so as to motivate their interest in math learning and confidence increasing. In such way, not only the good method, good solution and thinking can be broadened but also it is a valuable completion and improvement for the class.

\section{B. How to treat the innovation of students}

In order to nurture the students' innovative capacity, the teacher has to change his evaluation concept while paying attention on progress and improve the result and gradually be certain for the value pursue of evaluation. They should pay attention to the students in evaluation and to how to promote the students' development and how to nurture their creative ability. Firstly, the teacher has to be certain that the innovation of the primary and middle school students are totally different from the adults' innovation. That is the difference the students show in math learning progress from others, and even the wonderful thinking which are taken as error or absurd. All should be taken as creation. Do not grindingly expect the students to make an invention, creation and only that can be called creation. Secondly, the teachers should encourage students to have their own thinking. And this is the premise for innovation. When the students have different thinking or doing with others, the teachers should take this as the opportunity to encourage and introduce students to create and inspire and nurture their creation idea and do not just kill the bud status for their creative ideas. Secondly, the teacher should pay attention on students' needs, and minimizes the control for students and release the constraints. Sometimes we will find that the students are really smart and they have their own unique thinking and richer answer. As the teacher, what we need to do is to understand them better and fully pay attention on the differences of them. While we need respect the need for knowledge, ability and interest of different students and give them opportunity for activity, space for thinking. That is when teacher is evaluating the students' thinking and doing, he has to be careful and cannot simply use "right" or "wrong" as the evaluation.

\section{Strengthening the education introspection and accelerate the professional growth}

The teaching without introspection is a kind of low effective teaching. It can be only called at most as the shallow teaching. The formula for teacher's growth is "growth=experience+introspection". As a teacher, only when we continuously introspect from our teaching experiences, more mutual study, experience sharing, introspection and discussion related to education practice can be incurred and the bad teaching behavior in teaching activity can be remedied. To grow in research and grow in introspection, we need to take this opportunity to improve the teachers' combination of new concept with teaching ability as well as practice wisdom in education and make ourselves to become a researched based type, scholar type teacher. Therefore, the math teacher should always promote self professional growth through introspection to improve the educational teaching level. Such as the case mentioned above, in such case, when the student has different thinking or doing for this correction problem, if the teacher can carefully introspect in time, he will find that the impreciseness of the proposition or the answer is just not in full form and he will confirm and praise the student's different solution and even can let students to discuss different methods and compare the difference. When doing so, not only the students can learn better, and it also promotes the teachers' growth. And both teacher and student can acquire more. On the contrary, like introduced in this case, the teacher not only did not introspect on his behavior but also insisted on the standard answer and gave a cross for the student's correct doing and this does not have advantage for the math learning but also has disadvantage on the professional growth for teacher.

After all, establish a correct evaluation concept, it will smoothly promote and deepen the revolution meaning and therefore it needs all the teachers to persist and never abandon on this. They should learn carefully on the curriculum standard and understand the real essence of the spirit and make this evaluation to play positive role in the education progress.

\section{References}

[1] <Math curriculum standard for compulsory education> Beijing Normal University Press and Ministry of Education of Republic of China formulates, 2012.1. 